\title{
Evidence for a rheologically strong chemical mantle root beneath the Ontong-Java Plateau
}

\author{
E.R. Klosko, R.M. Russo*, E.A. Okal, W.P. Richardson ${ }^{1}$ \\ Department of Geological Sciences, Northwestern University, Evanston, IL 60208, USA
}

Received 10 August 2000; received in revised form 9 January 2001; accepted 10 January 2001

\begin{abstract}
Shear wave splitting measurements, in conjunction with studies of shear wave velocity structure, indicate that the Ontong-Java Plateau (OJP) large igneous province (LIP) has a thick, compositionally distinct root that diverts asthenospheric mantle flow beneath the Pacific plate. The OJP, the largest of Earth's LIPs, stands $2 \mathrm{~km}$ above adjacent Pacific abyssal plains and is composed of mantle plume derived volcanics erupted at 122 and $90 \mathrm{Ma}$. Surface wave tomography of the Plateau reveals a seismically slow upper mantle root that extends approximately to $300 \mathrm{~km}$ depth. The thickness and juxtaposition of the Plateau and the mantle root imply that the OJP is the preserved 'head' of a rising mantle plume formed in situ when the LIP erupted. Thus, it is a far-traveled body currently moving northwestwards with the Pacific plate. Shear wave splitting at four seismic stations along the northern margin of the OJP varies systematically: the fast axis of seismic anisotropy at three stations on the NE OJP margin trend NW, parallel to hotspot-defined Pacific absolute plate motion; at a fourth station, on the NW margin of the Plateau, the fast shear wave trend is NE. Upper mantle flow directions delineated by the shear wave splitting could thus represent mantle flow diverted around the leading, northwestern face of the rheologically strong, chemically distinct OJP root. In sum, the Plateau and its deep root appear to be similar to continental tectosphere, except for contrasting seismic velocities. (C) 2001 Elsevier Science B.V. All rights reserved.
\end{abstract}

Keywords: mantle plumes; large igneous provinces; S-waves; mantle flow; asthenosphere; Ontong-Java Plateau; tomography; tectonosphere; lithosphere

\section{Introduction}

Although a genetic relationship between flood basalts of large igneous provinces (LIPs) and mantle plumes has long been assumed [1-4], the

\footnotetext{
* Corresponding author.

1 Present address: Chevron Petroleum Technology Co., 935 Gravier Street, New Orleans, LA 70112, USA.
}

extent of upper mantle structures related to such plumes has only recently been appreciated $[5,6]$. The Ontong-Java Plateau (OJP), Earth's largest and thickest LIP, has an extensive, seismically slow upper mantle root [7] which has been moving WNW with the Pacific plate since its formation $120 \mathrm{Ma}[8,9]$.

We use shear wave splitting measurements from a four island passive broadband seismic network positioned on the Caroline Islands (Federated States of Micronesia) and on Nauru (Fig. 1), to 
shed light on the long-term juxtaposition of the OJP eruptives riding on the oceanic Pacific plate, and the remnant plume head extending into presumably flowing mantle several hundred kilometers beneath this plate. We show that the OJP can divert upper mantle flow, as manifested by our shear wave splitting measurements.

\section{Tectonic background}

The OJP stands $2 \mathrm{~km}$ above adjacent Pacific abyssal plains and is composed of mantle plume derived volcanics. The L-shaped Plateau is appar- ently buoyant: the complex Solomon Trench, along which Australian and Pacific lithosphere is currently subducting, is significantly indented where the OJP has entered the trench (Fig. 1). The OJP erupted at the Earth's surface in two main episodes: low potassium ocean island tholeiites of the western portion of the Plateau were emplaced at $122 \pm 3 \mathrm{Ma}$, and similar basalts of the eastern arm of the Plateau erupted at $90 \pm 4$ Ma [8,9]. Samples from DSDP site 289, ODP sites 803 and 807, and exposures of OJP basement on the Solomon Islands of Malaita, Santa Isabel, Ramos and Ulawa, where the OJP has been obducted onto the Solomon Islands Arc, yield ${ }^{40} \mathrm{Ar} /$

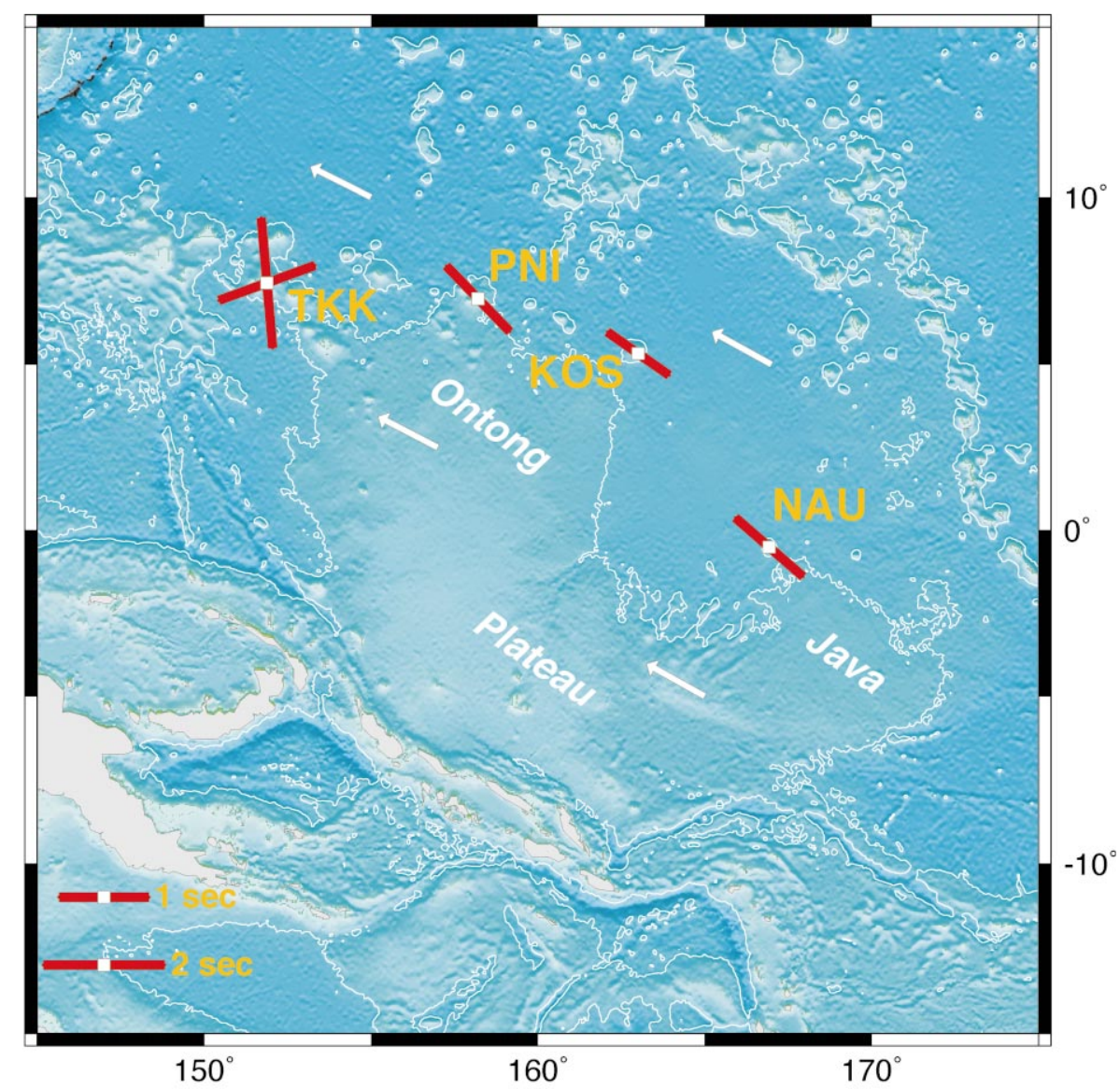

Fig. 1. Bathymetry of the OJP region, $4000 \mathrm{~m}$ contour shown in white [50]. Magenta lines are isodepth contours to top of subducted slabs. Seismometer stations (TKK, Chuuk; PNI, Pohnpei; KOS, Kosrae; NAU, Nauru) shown as white squares. Shear wave splitting measurements are shown as red bars, trending in the fast shear wave direction, length scaled by delay time (see key, lower left). White arrows are Pacific plate APM [33]. 
${ }^{39} \mathrm{Ar}$ dates with these bimodal ages, and two isotopically distinct magma sources are inferred for the 122 Ma lavas, whereas the $90 \mathrm{Ma}$ magmas include only one of these isotopic sources [9-11]. The thick basalts of the OJP eruptive phase represent high-degree (20-30\%) polybaric partial melting of a peridotitic mantle source [9]. The simplest interpretation of the volume, timing and chemistry of the OJP basement rocks is that they are the result of eruption from a single mantle plume 'head', although the time period between the two eruptive episodes is long. The latter could be related to plume head separation during transit across the $660 \mathrm{~km}$ seismic discontinuity [12].

The OJP formed in the south-central Pacific Basin at around $40^{\circ} \mathrm{S}, 160^{\circ} \mathrm{W}$ near or on one of the Farallon-Izanagi-Pacific triple junction spreading ridges [9]. Geoid anomalies over the OJP are uncorrelated with the Plateau itself indicating the structure is isostatically compensated, consistent with eruption of the Plateau flood basalts on a weak lithosphere, i.e. near a spreading ridge $[13,14]$. Since its eruption around $122 \mathrm{Ma}$, the OJP has moved generally WNW with the oceanic plates of the Pacific Basin on which it formed: initially probably with the Farallon plate, and more recently with the fast-moving Pacific plate. Cretaceous plate reconstructions of the $\mathrm{Pa}$ cific Basin are uncertain, but it is likely that both the Farallon plate and the small, young Pacific plate were slow-moving with respect to Pacific Basin hotspots at the time of OJP eruption [15]. However, given the current OJP location $\left(3^{\circ} \mathrm{S}, 160^{\circ} \mathrm{E}\right)$, it is clear that the OJP is fartraveled.

The Caroline Island chain, on which three of the four seismic stations used in this study were deployed, lies along the northern margin of the OJP (Fig. 1), and is most likely a hotspot track. Paleomagnetic and radiometric data show that the islands Chuuk (TKK), Kosrae (KOS) and Pohnpei (PNI), formed near the paleoequator between 1.4 Ma (KOS) and 11 Ma (TKK), although the zero-age (possibly active) member of the chain has yet to be identified [16]. Further east, the Republic of Nauru (site of the fourth station, NAU) is a small uplifted atoll with an estimated age of at least $40 \mathrm{Ma}$, but its exact genesis remains elusive (e.g. [17]).

\section{Splitting measurements: methodology and data}

Observations of shear wave splitting are commonly used to map past and present deformation in the upper mantle [18-22]. Shear wave splitting occurs when a linearly polarized shear wave enters an anisotropic region and splits into two orthogonal components of vibration. The split shear waves travel at different speeds, which are determined by the material properties of the anisotropic medium [23-26]. At the receiver, shear wave splitting is manifested as a noticeable time separation between the arrival of the fast and slow components of the shear phase.

It is a common assumption that upper mantle seismic anisotropy results from the preferred lattice orientation of olivine, the dominant upper mantle mineral $[27,24]$. Laboratory and numerical experiments show that olivine aggregate alignment occurs even at low strain and that the fast anisotropy axis of the crystals tends to align with the deformation extension direction [23-26]. Shear wave splitting observations of fast polarization azimuth, $\phi$, and delay time between fast and slow waves, $\delta t$, are interpreted to relate mantle anisotropy to deformation and flow, as a likely indication of the lineation direction and intensity of alignment or thickness of aligned olivine aggregates in the upper mantle $[19,20,28,29]$. In the Earth's upper mantle, the extensional axis of deformation can be related directly to upper mantle flow, and thus the fast shear wave polarization direction is nominally a measure of horizontal upper mantle flow.

For this study, we use shear wave splitting measurements from the four island passive broadband PASSCAL seismic array (Fig. 1) which operated from January 1994 to March 1996, with the original goal of performing a seismic tomography experiment for the OJP [7]. We measure shear wave splitting using teleseismic direct-S and core interacting shear waves (ScS, SKS, SKKS, PKS) after selecting events for which these phases arrive with near-vertical incidence, and are well isolated in 


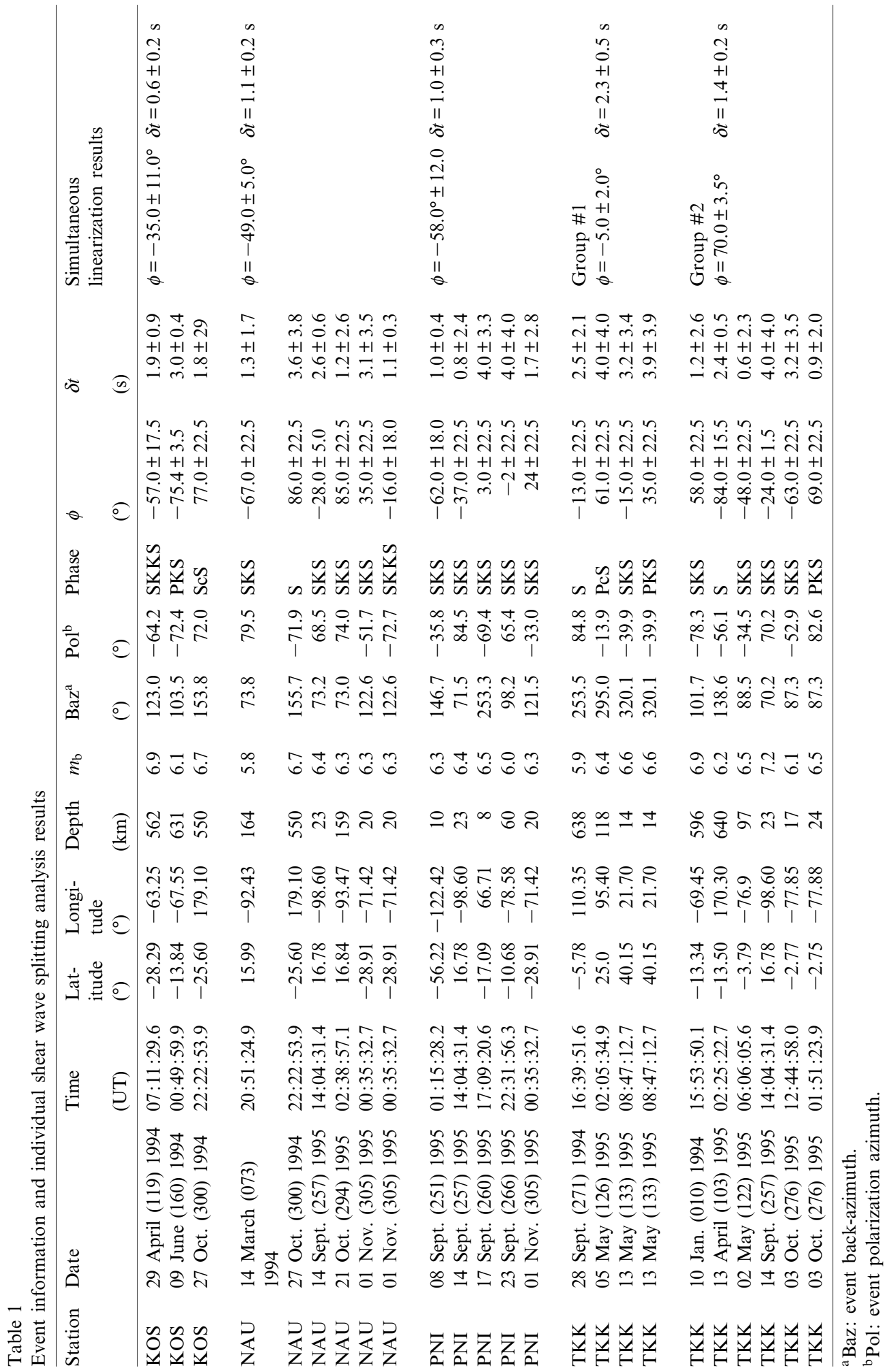


KOS

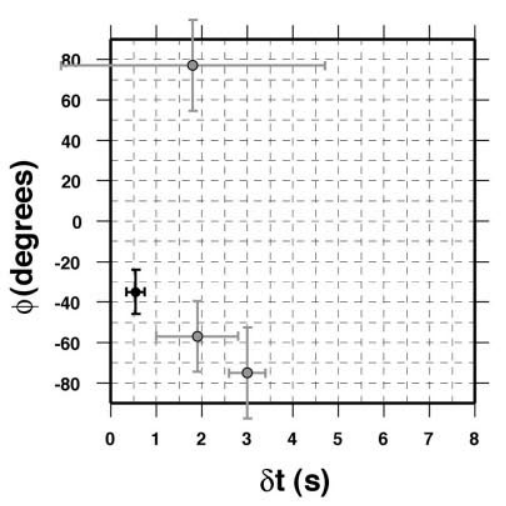

NAU

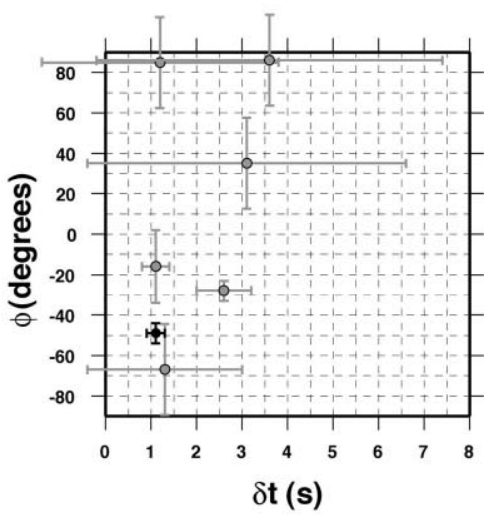

PNI

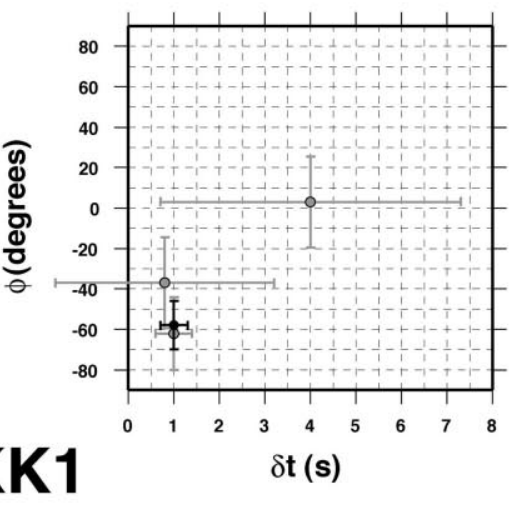

TKK1

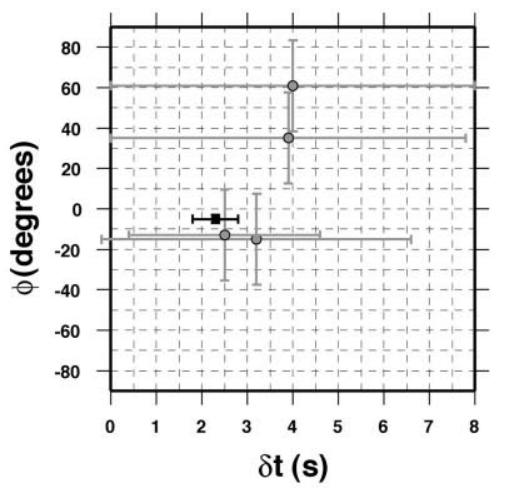

TKK2

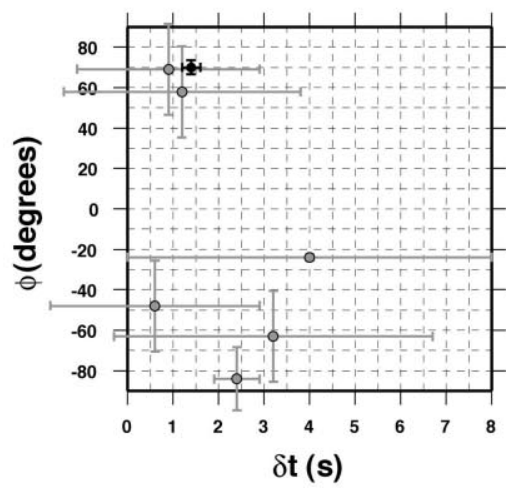

Fig. 2. Splitting results for each station represented by circles that correspond to a parameter set, $\phi$ and $\delta t$ (light gray, individual measurements; black, results from simultaneous linearization). Uncertainty (one standard deviation) in measurements shown by error bars.

the record. Events meeting these criteria are found at source-receiver distances between $87^{\circ}$ and $140^{\circ}$ for core-refracted phases, less than $30^{\circ}$ for $\mathrm{ScS}$, and in the range of $30-80^{\circ}$ for direct shear phases.
Following Silver and Chan [19], we model seismic anisotropy by grid-searching for the best parameters of fast polarization azimuth, $\phi$, and delay time, $\delta t$, that compensate for the effect of 
Event:1994.160 Sta:KOS Dist:129.5 Az:265.5 Baz: 103.5 -13.84N -67.56E 631.0km

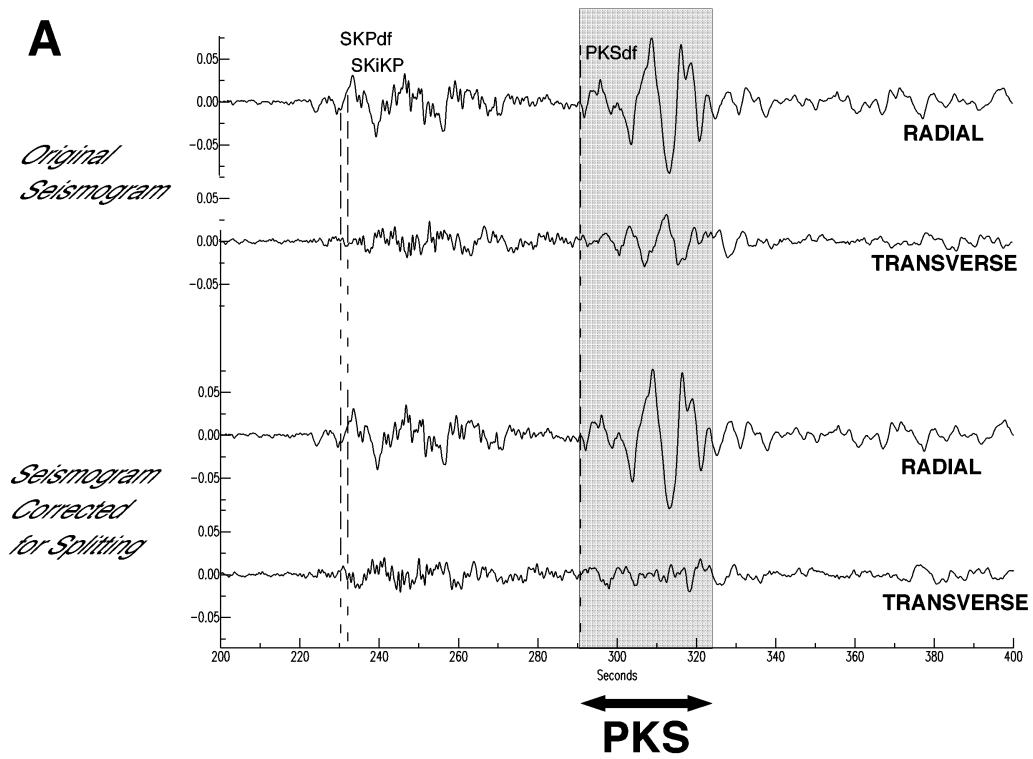

\section{B Superposition of Fast and Slow Waves}

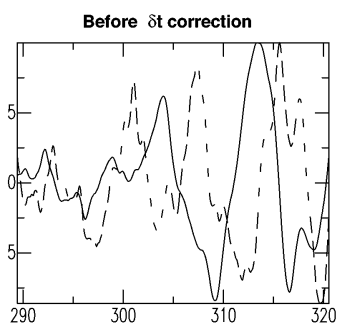

Radial/Transverse Plane Particle Motion

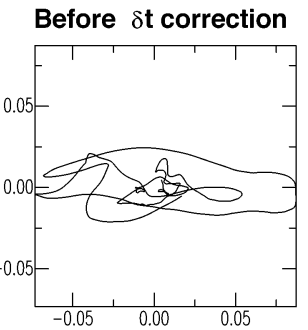

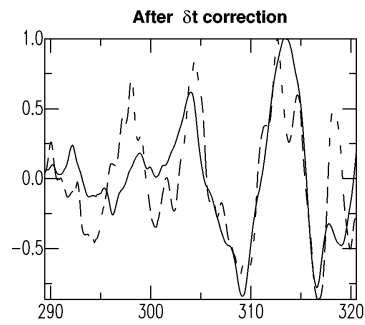

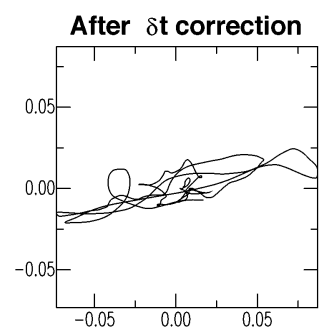

C Splitting Correction Contour Best Parameters:

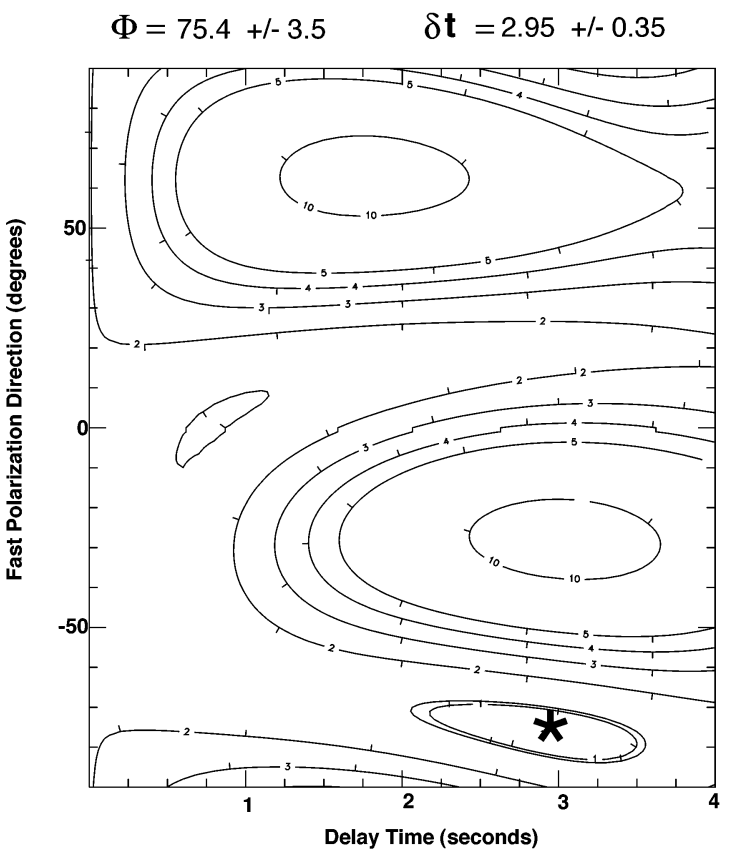


Fig. 3. Example of a split PKS wave recorded at KOS for great Bolivian earthquake. (A) Original signal (top two seismograms) rotated into radial and transverse directions according to the event back-azimuth. Corrected signal (bottom two seismograms) rotated to the fast polarization direction, $\phi$, and time shifted by the delay between the fast and slow waves, $\delta t$. (B) Superposition of the fast and slow components of the wave (top) representing the significance of the $\delta$ t correction before (left) and after (right) a rotation to $\phi$ has been applied. Particle motions (bottom) in the fast and slow frame, before (left) and after (right) splitting delay correction is applied. (C) Contour plot representing the parameters of $\phi$ and $\delta t$ that yield a minimum of energy on the transverse component of the signal (best parameters shown by star).

$\leftarrow$

shear wave splitting observed in the signal. For core-refracted phases, the best parameters minimize energy on the transverse component of the signal [19]. For direct-S and ScS, the best parameters linearize the radial/transverse particle motion, by minimizing the smaller eigenvalue of the polarization matrix [19]. To characterize seismic anisotropy from shear wave splitting measurements, we assume that $\phi$ is parallel to the fast axis of the anisotropic medium, consistent with laboratory observations and numerical modeling. The $\delta t$ value between the arrival of the fast and slow components is a gauge of the extent of the anisotropic region, under the assumption that delay increases with distance traveled, given a constant value of intrinsic anisotropy.

A common problem at island sites is high-amplitude seismic noise created by ocean swell at periods of 3-12 s (e.g. similar to the period of shear phases we are interested in $[30,31])$. To improve the quality of splitting measurements, we analyzed a suite of shear phases recorded at a given station for the splitting parameters that best linearize the phases' particle motions simultaneously [30]. Application of this method is also advantageous because it can reveal differences among consistently split phases arriving at the station from different back-azimuths.

\section{Splitting measurements: results}

We examined 18 events, which yielded 24 measurements of shear wave splitting at the four stations (Table 1, EPSL Online Background Dataset $^{2}$ ). Despite the noise inherent in the ocean

\footnotetext{
${ }^{2}$ http://www.elsevier.nl/locate/epsl, mirror site: http:// www.elsevier.com/locate.epsl
}

island setting of the stations, for large events $\left(m_{\mathrm{b}}>5.8\right)$ the data was adequate for detection of splitting. The distribution of results for single events at the individual stations is shown in Fig. 2. Fig. $3 \mathrm{~A}-\mathrm{C}$ shows the determination of splitting parameters for a single arriving shear phase, PKS, recorded at KOS from the great 1994 Bolivian deep earthquake. Note that although there is clearly anomalous energy on the transverse component of the PKS seismogram (Fig. 3A), the signal to noise level is low even for this very highmagnitude event. Ultimately, this splitting measurement yields the result shown by Fig. 3C. Table 1 and Figs. 2 and 3 illustrate the need for the simultaneous linearization technique.

By performing simultaneous linearizations of multiple events [30], we corrected the splitting for each event and found uncertainties to be significantly reduced. For KOS and NAU, we obtained splitting parameters using the simultaneous linearization technique for all three and all six individual events, respectively (Table 1, Fig. 4). Despite five individual splitting measurements at PNI, simultaneous linearization of all five yielded poor results, indicative of at least two inconsistent sets of splitting parameters. Trial subgroupings demonstrated that three events (see Table 1: events 95.251, 95.257 and 96.260) yielded one good set of best-fitting parameters. The remaining two events (95.266 and 95.305) were not consistent with a single set of splitting parameters, most likely because although anomalous energy is visible on the transverse components of both events, signal to noise is very low, and split phases are likely swamped by randomly polarized noise. Thus, we only present results from the simultaneous linearization of the three consistent events for PNI (Table 1).

Similarly, when we used all events for TKK in the simultaneous linearization (see Table 1), we 
NAU Summed Error for 6 Events

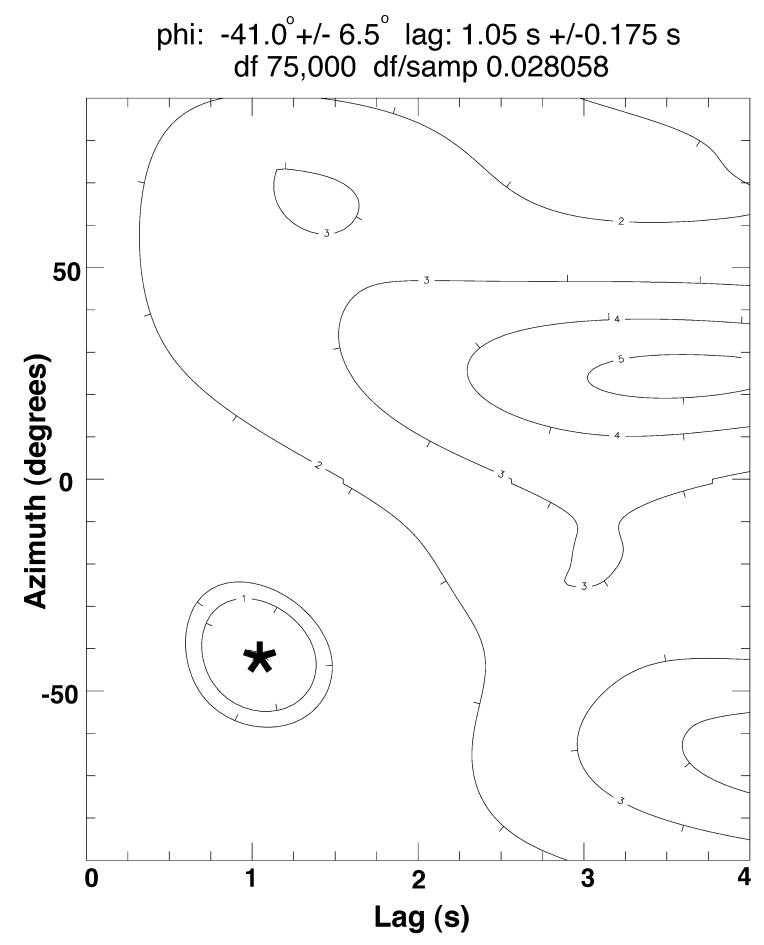

Fig. 4. Results for NAU: Contours of energy which show the minimization of the smaller eigenvalue of the polarization matrix for all possible $\phi$ and $\delta t$ values. Minimum energy is denoted by a star.

found that only four events were well corrected (e.g. linearized) by the best-fitting splitting parameters for the group; the remaining six events retained elliptical particle motions in the supposed fast-slow component frame. However, we found that the data could be divided into two groups according to station-event back-azimuth each of which yielded good simultaneous linearization splitting parameters. Group 1 includes shear phases arriving from back-azimuths between $254^{\circ}$ and $320^{\circ}$, and group 2 events range from $70^{\circ}$ to $140^{\circ}$. The simultaneous splitting parameters for each group are shown in Table 1 and Fig. 2. Contours delimiting the range of parameters that best linearize the particle motion from both back-azimuth groups are shown in Fig. 5A,B. With a larger data set it might be possible to investigate the characteristics of the two groups in terms of two (or more) anisotropic layers
[32], but with the limited data available to us this was not possible.

The splitting measurements yield $\phi$ directions trending northwest (between $\mathrm{N} 35^{\circ} \mathrm{W}$ and $\mathrm{N} 58^{\circ} \mathrm{W}$ ) at three of the four stations, $4-27^{\circ}$ from the trend of the absolute plate motion (APM) of the Pacific plate (Fig. 1) [33], consistent with the majority of splitting measurements made at other Pacific plate ocean stations [31,30]. At TKK, the westernmost station, $\phi$ trends $\mathrm{N} 70^{\circ} \mathrm{E}$ for events from Baz group 2, almost at right angles to both local Pacific APM and the fast polarization directions at the other stations. For the Baz group 1 events at TKK, $\phi$ trends $\mathrm{N} 5^{\circ} \mathrm{W}$, roughly $57^{\circ}$ from the local APM azimuth. The values of $\delta t$ for the three stations along the NE side of the OJP (PNI, KOS, NAU) stations are $1.0 \pm 0.3,0.6 \pm 0.2$ and $1.1 \pm 0.2 \mathrm{~s}$, respectively. These values are consistent with other Pacific Basin ocean island splitting observations [31]. However, the delay times at TKK are $2.3 \pm 0.5 \mathrm{~s}$ (Group 1) and $1.4 \pm 0.2 \mathrm{~s}$ (Group 2), the largest delay times yet observed for shear wave splitting in any ocean basin.

\section{Discussion of splitting results}

The $\phi$ azimuths measured at NAU, KOS and PNI generally parallel local APM directions: the deviations are comparable to those obtained by Russo and Okal [31] and Wolfe and Silver [30] at island sites throughout the Pacific basin. Thus, we interpret our shear wave splitting measurements at these stations as proxies for shear flow in the asthenosphere beneath the rigid Pacific lithosphere, engendered as the plate moves WNW toward the western Pacific subduction zones. In effect, the asthenosphere here acts as a decoupling layer between plate and the deep mantle. It is unlikely that these measurements include a significant contribution from aligned olivine in the lithospheric plate since the olivine fabric in the mantle lithosphere should be parallel to the plate fossil spreading direction, which in the environs of the OJP trends NNW [34].

In previous contributions [31,35], we have shown that azimuthal anisotropy can be strongly 
A

Group \#1 TKK Summed Error for 4 Events phi: $-5.0^{\circ}+/-2.0^{\circ}$ lag: $2.25 \mathrm{~s}+/-0.45 \mathrm{~s}$ df $64.0 \mathrm{df} / \mathrm{samp} 0.03322$

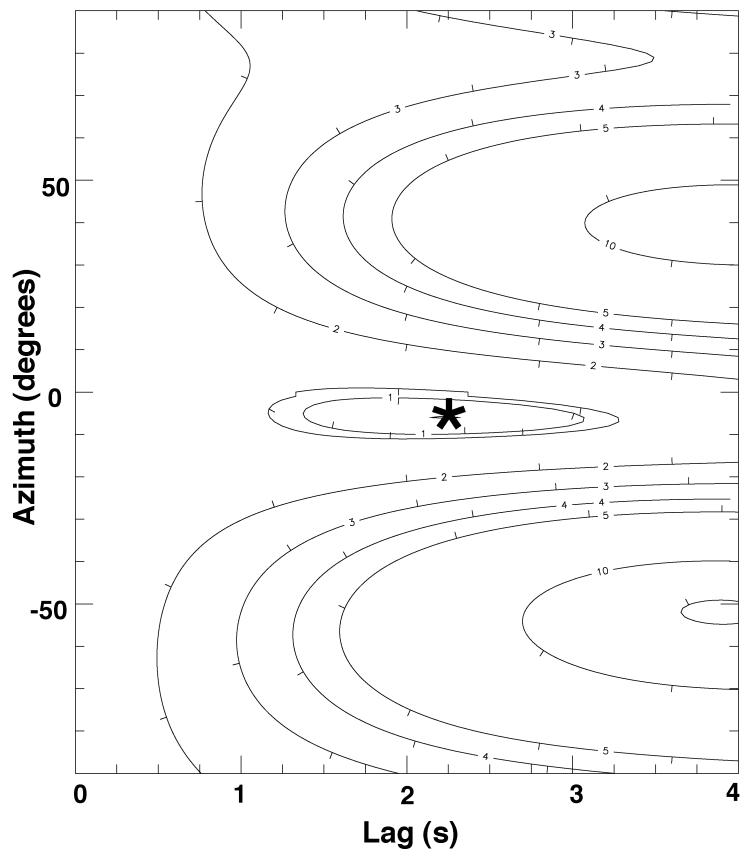

\section{B Group \#2} TKK Summed Error for 6 Events phi: $70.0^{\circ}+/-3.5^{\circ}$ lag: $1.35 \mathrm{~s}+/-0.225 \mathrm{~s}$ df $94.0 \mathrm{df} / \mathrm{samp} 0.020659$

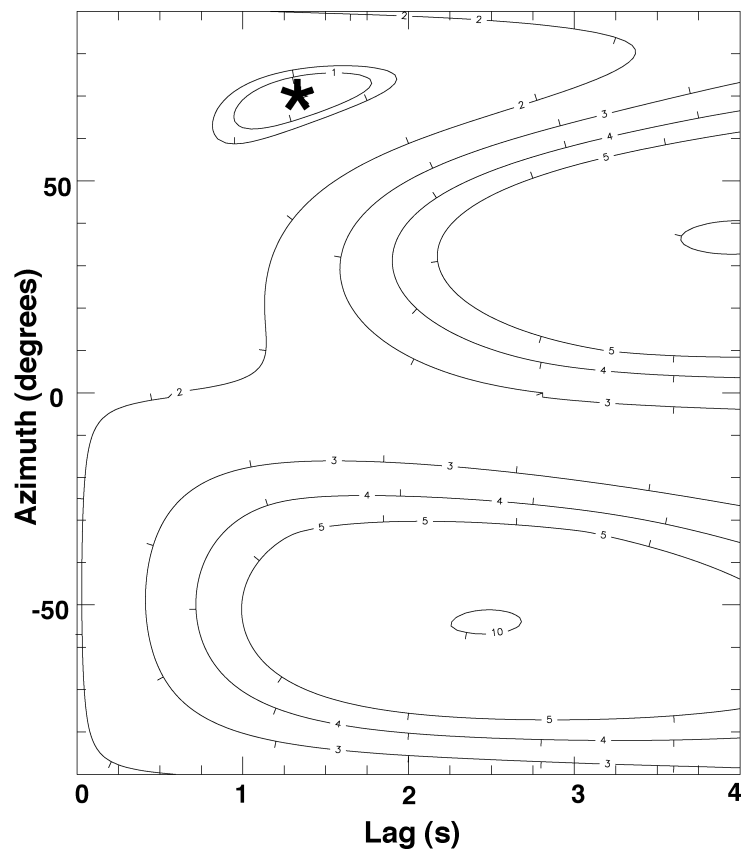

Fig. 5. Results for TKK: energy contours for two back-azimuth groups: (A) Baz group 1 (254-320 ${ }^{\circ}$ and (B) Baz group 2 $\left(70-140^{\circ}\right)$, in the same convention as Fig. 4.

perturbed in the vicinity of hotspot structures; indeed, no clear seismic anisotropy has been observed to date at active ocean island hotspots. The 'normal' APM-parallel result at KOS is then particularly interesting since this very young island (1.4 Ma [16]) might have been expected to feature no azimuthal anisotropy, as is the case for Tahiti ( $\sim 1 \mathrm{Ma}$ [36]) and the southern part of the Big Island of Hawaii [31,35]. The measurement at KOS suggests that any possible active member of the Caroline chain (yet to be discovered) is so distant and/or weak that the plume flow does not affect asthenospheric mantle fabrics beneath KOS. In this respect, our results at KOS are similar to Wolfe and Silver's [30] findings at Rarotonga (1-2 Ma [37]), and Russo and Okal's [31] result at Pitcairn.

In contrast to the splitting at NAU, PNI and KOS, upper mantle anisotropy beneath TKK is anomalous for the Pacific basin, with one NE fast shear trend nearly perpendicular to APM and to the directions at the other sites, for shear phases arriving from eastern back-azimuths, and a $\mathrm{N}$ trending fast axis for phases incident from the west (Fig. 1). The observation of dependence of splitting parameters on azimuth of phase arrival can be interpreted in several ways: as departures of the anisotropy from the simple hexagonally symmetric horizontal axis model commonly used to interpret splitting results, such as plunging symmetry axis [38], as two superposed layers of anisotropy [32], or as lateral variability of anisotropy at sublithospheric depths [39]. Because the data at TKK are limited to arrivals from only two narrow back-azimuth ranges, it is impossible to determine which, if any, of these possibilities is valid. However, we favor lateral variability of anisotropy, since the most likely two-layer model, anisotropic lithosphere over asthenosphere with a different anisotropy, has not been observed at 


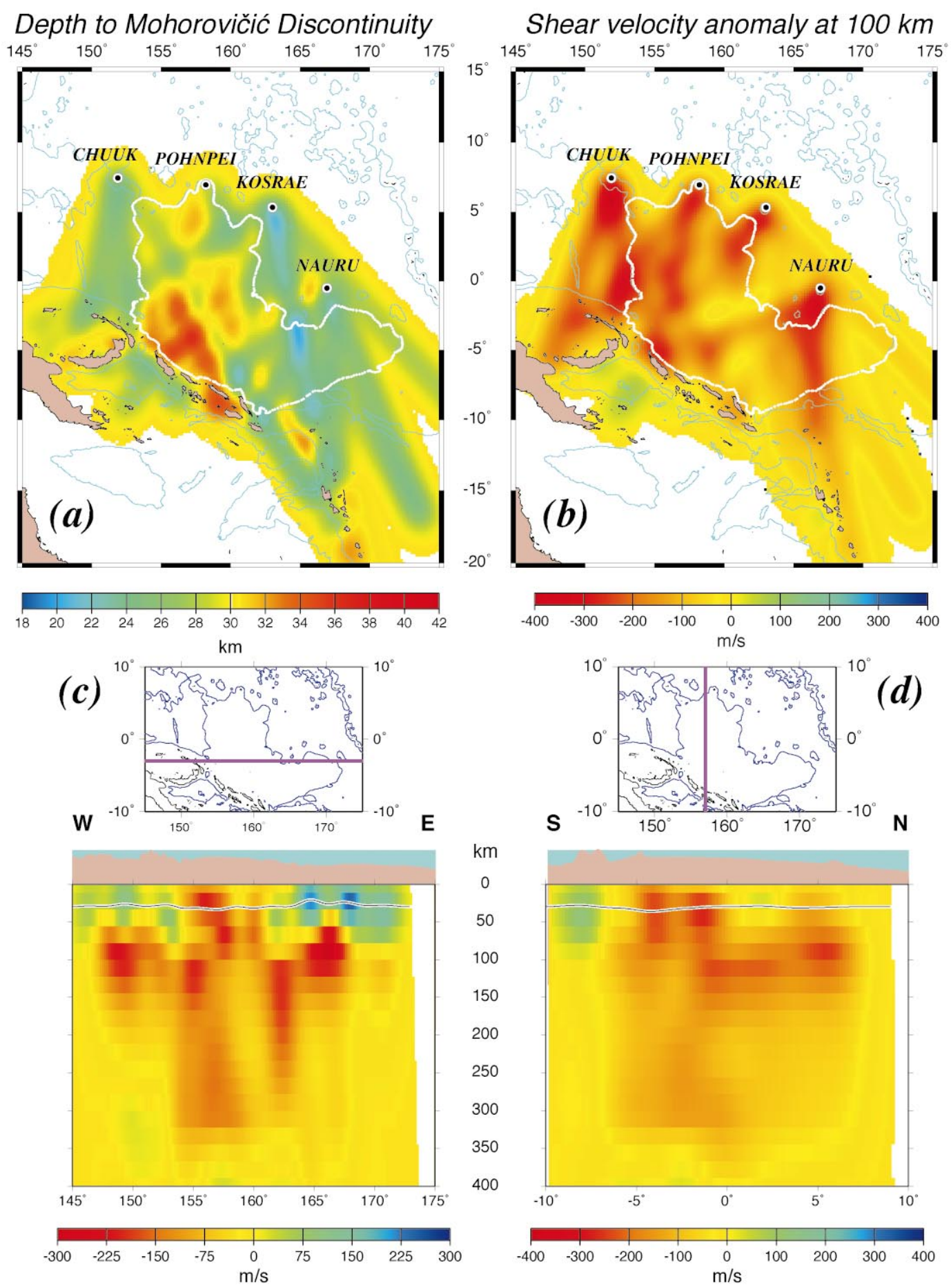

Fig. 6. Tomography results: (a) Depth to the Mohorovičić discontinuity; note that even the thinnest parts of the OJP crust (bounded by the white line along the $4000-\mathrm{m}$ contour) are at least $20 \mathrm{~km}$. (b) Horizontal section at $100 \mathrm{~km}$; paths across the OJP are seismically slow for shear waves. (c) W-E section (section line in magenta, top panel) across the OJP; note slow velocity anomaly down to around $350 \mathrm{~km}$. (d) N-S section across the OJP. 
any station in the southern Pacific. Also, given the magnitudes of the delay times observed $(2.3 \pm 0.5$ and $1.4 \pm 0.2 \mathrm{~s}$ ), it is unlikely that the anisotropy can include a steep plunge since this increases the likelihood of coincidence of propagation paths and symmetry, leading to null splitting observations. In fact, we observed no null measurements at TKK. Thus, we consider it unlikely that these measurements represent contributions from lithospheric fossil spreading fabrics (which trend NNW), or from strongly plunging anisotropy, and the simplest interpretation is that the horizontal component of asthenospheric flow beneath and to the east of TKK trends NE or SW, whereas it is $\mathrm{N}-\mathrm{S}$ just to the west of the atoll. These directions cannot be related to asthenospheric shear induced by drag of a flat-bottomed lithospheric plate over the underlying mantle, as at PNI, KOS and NAU. The clear difference between the two flow directions implies that the mantle flow field varies over short spatial scales in the vicinity of TKK.

It is unlikely that the measurements at TKK are perturbed by hotspot processes: the Caroline hotspot, which has no apparent influence on measurements at the nearer sites KOS and PNI, is simply too far away, and the TKK edifice is colder, in terms of thermal history, than sites such as Kauai or Rarotonga, for which good agreement between the directions of seismic anisotropy and APM has been reported [30,35]. Finally, it is unlikely that anomalous crustal thickness can be directly related to the odd splitting at TKK, since even at Rangiroa on the Tuamotu Plateau, a site underlain by a $35-\mathrm{km}$ thick crust [40] comparable to that of the OJP, $\phi$ and local APM trends coincide [31]. Thus, it is clear that the deviation observed at TKK between the APM azimuth and anisotropy can be ascribed neither to the influence of an active magmatic system, nor to a relatively thin structure like the Tuamotu Plateau.

\section{OJP structure and mantle flow}

Richardson et al. [7] produced a three-dimensional tomography of the structure underlying the OJP by inverting shear velocity profiles obtained along individual paths crossing the plateau. The tomographic results indicate the presence of an approximately cylindrical slow velocity anomaly below the OJP reaching a depth of over $300 \mathrm{~km}$ and with a radius of $600 \mathrm{~km}$ (Fig. 6). Inverted shear velocities beneath the OJP are about 5\% slow with respect to the PREM Earth model [41], and are seismically slow relative to surrounding asthenospheric mantle, observed throughout the Pacific Basin at depths of 100-250 km (e.g. $[42,43])$. The slow anomaly extends to depths generally considered to be greater than the bottom of the asthenospheric channel. Given its shape, its depth extent and its clear association with the OJP eruptives, it is likely that the sub-OJP slow velocity anomaly is a remnant mantle plume head [7].

Similar low velocity structures, interpreted as mantle plume heads, have been imaged tomographically to depths of several hundred kilometers beneath the Paraná flood basalts of central South America [5] and the Deccan Traps of NW India [6]. The Paraná basalts erupted 134 to 129 Ma [44], and the Deccan traps have a well-documented peak of activity from 65 to $60 \mathrm{Ma}$ [45]. Both South America and India have traveled a considerable distance with respect to the deep mantle since the flood basalt volcanism on each continent. Eruption onto and emplacement within the rheologically strong thick cratonic roots of South America and India provide a reasonable explanation for the preservation of these plume structures in the upper mantle beneath the surface eruptives. Note that no such explanation can be invoked for the preservation of the upper mantle slow velocity anomaly beneath the OJP, since the latter has ridden on the much thinner $(\sim 100 \mathrm{~km})$ lithosphere of the Pacific plate since at least the late Mesozoic, and the velocity anomaly extends far below this lithosphere into and beyond what is normally considered flowing asthenospheric mantle beneath the Pacific plate (e.g. [42,43]). The existence of the slow velocity plume head root beneath the OJP eruptives today strongly suggests that the root has moved with the Plateau since its formation.

We can explain both the presence of the OJP tomographic root beneath the far-traveled Plateau 


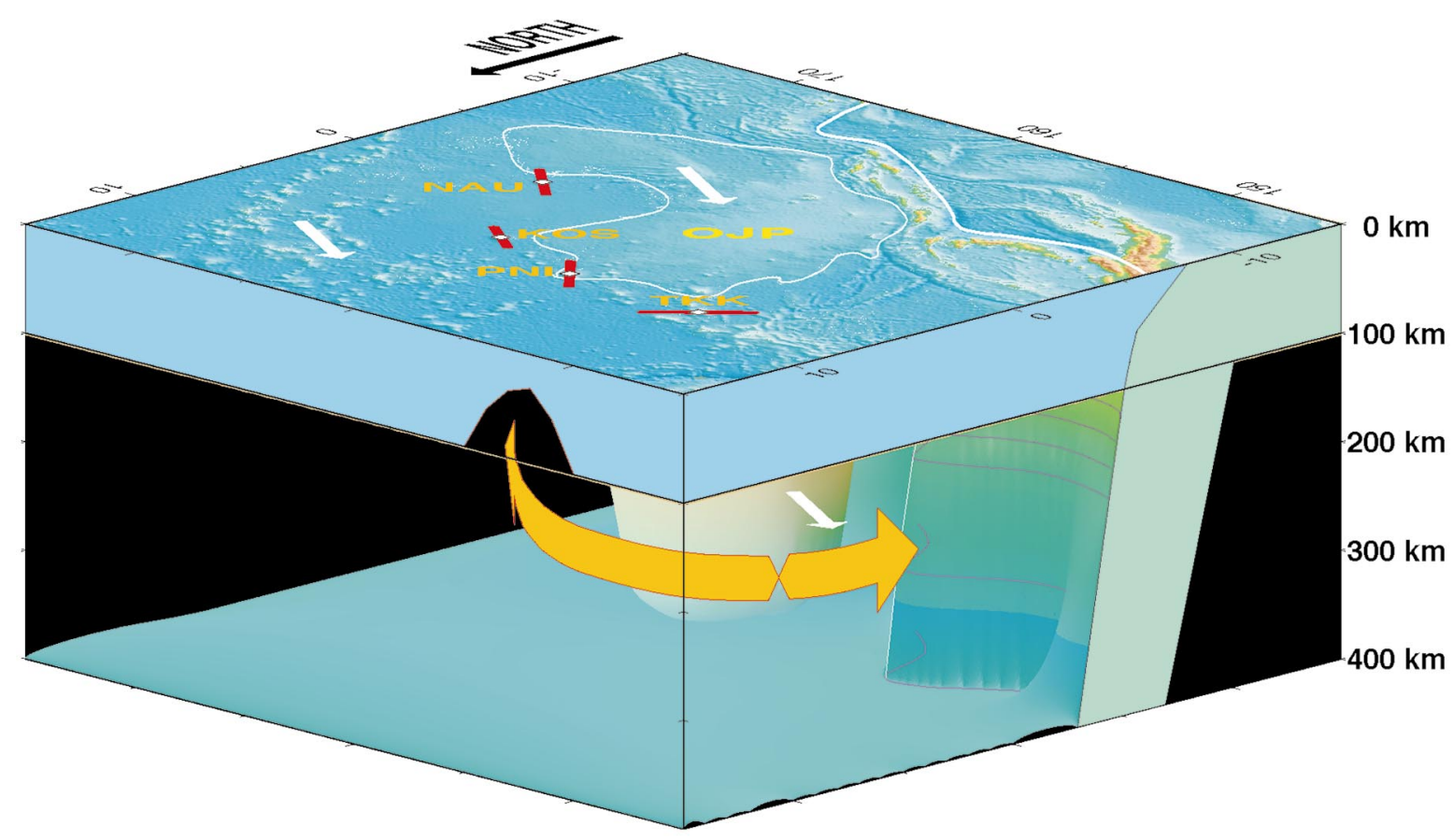

Fig. 7. Interpretive view of the OJP root (yellow), moving WNW with the Pacific plate (white arrows), diverting asthenospheric mantle flow (orange arrows). Note splitting measurements (red bars) on surface are parallel to immediately underlying asthenospheric flow directions. Splitting at TKK corresponding to arrivals from eastern back-azimuths is shown.

and the anomalous TKK shear wave splitting measurement if we invoke a rheologically strong root coupled to the Pacific plate lithosphere. Given strength, the upper mantle root can act like a very thick lithospheric bulge which, moving WNW with the Pacific plate APM relative to the deeper mantle, diverts asthenospheric mantle flow (Fig. 7). Thus, the pattern of shear wave splitting, including both the odd fast shear wave azimuth and high-delay time splitting measurement at TKK can be explained: asthenospheric mantle flow is displaced forward of the OJP root and strain should be higher, and consequent fabric development stronger, along the leading edge of the OJP root than along its NE face, where delay times and splitting azimuths are normal. Assuming the root is strong and was coupled to Pacific lithosphere sometime before the Pacific plate began rapid motion with respect to Pacific Basin hotspots, we can explain the root's presence beneath the Plateau today. Slow relative motion of the OJP with respect to the underlying mantle for some time after its eruption would have allowed the OJP root to cool and strengthen sufficiently to resist dispersal by asthenospheric flow.

The variable flow directions apparent at TKK may reveal the scale of asthenospheric flow diverted around the OJP root: shear phases incident from eastern back-azimuths (i.e. sampling the mantle immediately adjacent to the OJP root) reveal flow perpendicular to the leading edge of the OJP root. However, phases arriving from the west show a trend that is not simply related to OJP structure, but may be indicative of flow that is transitional between diverted flow and APM flow. If this is the case, then the perturbed flow field exists in the order of $3^{\circ}(\sim 330 \mathrm{~km})$ from the leading edge of the OJP, given the location of TKK.

We note the apparent paradox of a seismically slow upper mantle root that is seemingly strong enough to perturb asthenospheric flow. Typically, slow seismic velocity anomalies are associated with elevated temperatures, and relatively high 
temperatures indicate rheologic weakness. It is unlikely, given its Early Cretaceous eruption age, that the OJP retains a thermal anomaly related to its eruption. More recent volcanism at 90 and $34 \mathrm{Ma}$ [9-11] could have reheated the OJP root, but reheating should also have resulted in weakening of the root; since the splitting measurement is an instantaneous measure of asthenospheric flow, it is unlikely that any reheating was sufficient to reduce the root to the strength of the surrounding flowing asthenosphere. Furthermore, the seismic anomalies due to reheating of oceanic lithosphere and upper mantle by the Hawaiian hotspot are undetectable after $30 \mathrm{Ma}$ [46]. The OJP root is seismically distinct and seemingly strong, indicating in all likelihood that it is primarily a chemical anomaly and not a thermal anomaly. Finally, a study of seismic attenuation of the OJP root has shown that the root has higher $Q$ than surrounding mantle [47], indicating that remanent thermal anomalies are unlikely.

The chemical anomaly associated with the OJP root slow shear wave velocities could be partly explained by a low density residuum, produced by high-degree partial melting $(20-30 \%$; [9]) of a peridotite source with partitioning of $\mathrm{Fe}$ into the melt fraction and lighter $\mathrm{Mg}$ into the residuum, yielding the thick (33 $\mathrm{km}$ on average) basalts of the OJP. Such melt partitioning could produce a buoyant, seismically slow root. However, it would be difficult if not impossible to produce the extreme thickness of the OJP root, given the estimated degree of partial melting and the thickness of the Plateau basalts: $30 \%$ partial melting that yields $33 \mathrm{~km}$ of basalt Plateau should leave behind a restite in the order of $80 \mathrm{~km}$ thick, not 300 $\mathrm{km}$ [9]. Also, it is not clear whether a Mg-rich restite would necessarily be rheologically stronger than surrounding asthenospheric mantle, as the OJP root seems to be. Some other chemical constituent or process is therefore necessary in order to explain the large volume upper mantle chemical anomaly represented by the OJP root. We note that in addition to shallow chemical differentiation due to pressure release melting, processes of plume head formation at the core-mantle boundary and plume rise across the $660 \mathrm{~km}$ seis- mic discontinuity could result in chemical differentiation of the rising plume material [12].

\section{Conclusions}

We use measurements of shear wave splitting to map deformation in the upper mantle beneath Micronesian stations along the Caroline Islands and Nauru. Results show a mantle flow pattern diverted around the thick root beneath the OJP, which lies to the south of these stations. Since the OJP is underlain by an upper mantle root approximately $300 \mathrm{~km}$ thick, lying directly beneath the $122 \mathrm{Ma}$ eruptives of the Plateau, this root is a long-lived, far-traveled structure, seismically slow and distinct with respect to surrounding asthenospheric upper mantle. These results show the OJP root, as previously identified from seismic tomography, to be strong enough to divert asthenospheric mantle flow. The root is probably chemically depleted, but may have an unidentified chemical constituent that renders it seismically slow and rheologically strong. In many ways, the OJP is similar to a thick-rooted continental craton. Its history and chemistry imply that the root represents the residue from intense hotspot plume head activity. Similar plume head structures have been identified in place beneath flood basalt provinces in South America and India, although the OJP, emplaced into an oceanic plate, is unique in that it did not intrude into deep continental roots that explain the far-traveled nature of the Paraná and Deccan remnant structures. The similar seismically slow thick anomalies of all three hotspot plume heads imply that chemical differentiation at the core-mantle boundary, presumably the source of these mantle plumes, is strong and results in long-lived compositional anomalies [48]. Resultant buoyancy of these structures may indicate that plume head remnants ultimately accrete to continental masses and represent a significant component of continental growth, increasing the overall volume of tectosphere [49]. Thus, mantle plumes could contribute to the long-term chemical differentiation of the planet. 


\section{Acknowledgements}

We thank Clive Neal, Martin Flower, Liz Widom, Craig Bina and Alan Brandon for guiding our thinking about OJP root composition. Suzan van der Lee and Guust Nolet provided indispensable help with shear wave tomography. We thank Cecily Wolfe and Paul Silver for providing us with their splitting analysis code. The Micronesian PASSCAL deployment was supported by National Science Foundation Grant number EAR-93-16396 to E.A.O.; its operation and maintenance owed greatly to our many friends on the islands.[SK]

\section{References}

[1] W.J. Morgan, Convection plumes in the lower mantle, Nature 230 (1971) 42-43.

[2] I.H. Campbell, R.W. Griffiths, Implications of mantle plume structure for the evolution of flood basalts, Earth Planet. Sci. Lett. 99 (1990) 79-93.

[3] M.A. Richards, D.L. Jones, R.A. Duncan, D.J. DePaolo, A mantle plume initiation model for the Wrangellia flood basalt and other oceanic plateaus, Science 254 (1991) 263267.

[4] M.F. Coffin, O. Eldholm, Large igneous provinces: crustal structure, dimensions, and external consequences, Rev. Geophys. 32 (1994) 1-36.

[5] J.C. VanDecar, D.E. James, M. Assumpçao, Seismic evidence for a fossil mantle plume beneath South America and implications for plate driving forces, Nature 378 (1995) 25-31.

[6] B.L.N. Kennett, S. Widiyantoro, A low seismic wavespeed anomaly beneath northwestern India: a seismic signature of Deccan plume?, Earth Planet. Sci. Lett. 165 (1999) 145-155.

[7] W.P. Richardson, E.A. Okal, S. van der Lee, Rayleighwave tomography of the Ontong-Java Plateau, Phys. Earth Planet. Inter. 118 (2000) 29-51.

[8] J.J. Mahoney, M. Storey, R.A. Duncan, K.J. Spencer, M. Pringle, Geochemistry and age of the Ontong-Java Plateau, in: M.S. Pringle, W.W. Sager, W.V. Sliter, S. Stein (Eds.), The Mesozoic Pacific: Geology, Tectonics and Volcanism, Geophysical Monograph 77, 1993, pp. 233261.

[9] C.R. Neal, J.J. Mahoney, L.W. Kroenke, R.A. Duncan, M.G. Petterson, The Ontong-Java Plateau, large igneous provinces, in: J.J. Mahoney, M.F. Coffin (Eds.), Continental, Oceanic and Planetary Flood Volcanism, AGU Geophysical Monograph 100, 1997, pp. 183-216.

[10] R. Moberly, S.O. Schlanger, M. Baltuck, J.A. Bergen, W.E. Dean, P.A. Floyd, N. Fujii, J.A. Haggerty, J.G.
Ogg, S. Premoli, S. Isabella, S. Andre, G. Rainer, W.V. Sliter, J.M. Whitman, Initial reports of the Deep Sea Drilling Project covering Leg 89 of the cruises of the Drilling Vessel Glomar Challenger, Yokohama, Japan, to Noumea, New Caledonia, October-November, 1982, in: R.L. Larson, S. Orlofsky (Eds.), Initial Report of theDeep Sea Drilling Project 89, US Government Printing Office, Washington, DC, 1986.

[11] W.H. Berger, L.W. Kroenke, L.A. Mayer, J. Backman, T.R. Janecek, L.A. Krissek, M. Leckie, M. Lyle, F. Bassinot, R. Corfield, M. Delaney, R. Hagen, E. Jansen, C. Lange, I.L. Lind, J. Marsters, D. Mosher, R. Musgrave, M. Prentice, J. Resig, H. Schmidt, R. Stax, M. Storey, K. Takahashi, T. Takayama, J. Tarduno, R. Wilkens, G. $\mathrm{Wu}$, The record of Ontong-Java Plateau; main results of ODP Leg 130, Geol. Soc. Am. Bull. 104 (1992) 954 972.

[12] D. Bercovici, J. Mahoney, Double flood basalts and plume head separation at the 660 kilometer discontinuity, Science 266 (1994) 1367-1369.

[13] E.A. Okal, A. Cazenave, A model for the plate tectonic evolution of the east-central Pacific based on SEASAT investigations, Earth Planet. Sci. Lett. 72 (1985) 99-116.

[14] D.T. Sandwell, K.R. MacKenzie, Geoid height versus topography for oceanic plateaus and swells, J. Geophys. Res. 94 (1989) 7403-7418.

[15] D.C. Engebretson, A. Cox, R.G. Gordon, Relative motions between oceanic and continental plates in the Pacific basin, Geol. Soc. Am. Spec. Pap. 206, 1985.

[16] B.H. Keating, D.P. Mattey, J. Naughton, C.E. Helsley, Age and origin of Truk Atoll, eastern Caroline Islands; geochemical, radiometric-age, and paleomagnetic evidence, Geol. Soc. Am. Bull. 95 (1984) 350-356.

[17] P.J. Hill, G. Jacobson, Structure and evolution of Nauru Island, central Pacific ocean, Aust. J. Earth. Sci. 36 (1989) 365-381.

[18] J.R. Bowman, M. Ando, Shear-wave splitting in the upper-mantle wedge above the Tonga subduction zone, Geophys. J. R. Astron. Soc. 88 (1987) 25-41.

[19] P.G. Silver, W.W. Chan, Shear-wave splitting and subcontinental mantle deformation, J. Geophys. Res. 96 (1991) 16429-16454.

[20] R.M. Russo, P.G. Silver, Trench-parallel flow beneath the subducted Nazca plate from seismic anisotropy, Science 263 (1994) 1105-1111.

[21] R.M. Russo, P.G. Silver, M. Frank, A.B. Ambeh, D.E. James, Shear-wave splitting in northeast Venezuela, Trinidad, and the eastern Caribbean, Phys. Earth Planet. Inter. 95 (1996) 251-275.

[22] E.R. Klosko, F.T. Wu, H.J. Anderson, D. Eberhart-Phillips, T.V. McEvilly, E. Audoine, M.K. Savage, K.R. Gledhill, Upper mantle anisotropy in the New Zealand region, Geophys. Res. Lett. 26 (1999) 1497-1500.

[23] N.I. Christensen, The magnitude, symmetry and origin of upper mantle anisotropy based on fabric analyses of ultramafic tectonites, Geophys. J. R. Astron. Soc. 76 (1984) 89-111. 
[24] A. Nicolas, N.I. Christensen, Formation of anisotropy in upper mantle peridotites: a review, in: K. Fuchs, C. Froidevaux (Eds.), Composition, Structure and Dynamics of the Lithosphere-Asthenosphere System, Geodynamics Series 16, 1987, pp. 111-123.

[25] N.M. Ribe, Seismic anisotropy and mantle flow, J. Geophys. Res. 94 (1989) 4213-4223.

[26] D. Mainprice, P.G. Silver, Interpretation of SKS-waves using samples from the subcontinental lithosphere, Phys. Earth Planet. Int. 78 (1993) 257-280.

[27] H. Hess, Seismic anisotropy of the uppermost mantle under oceans, Nature 203 (1964) 629-631.

[28] M. Ando, ScS polarization anisotropy around Pacific Ocean, J. Phys. Earth 32 (1984) 179-195.

[29] L.P. Vinnik, V. Farra, B. Romanowicz, Azimuthal anisotropy in the Earth from observations of SKS at GEOSCOPE and NARS broadband stations, Bull. Seismol. Soc. Am. 79 (1989) 1542-1558.

[30] C.J. Wolfe, P.G. Silver, Seismic anisotropy of oceanic upper mantle: shear-wave splitting methodologies and observations, J. Geophys. Res. 103 (1998) 749-771.

[31] R.M. Russo, E.A. Okal, Shear-wave splitting and upper mantle deformation in French Polynesia: evidence for small-scale heterogeneity related to the Society hotspot, J. Geophys. Res. 103 (1998) 15089-15107.

[32] P.G. Silver, M.K. Savage, The interpretation of shearwave splitting parameters in the presence of two anisotropic layers, Geophys. J. Int. 119 (1994) 949-963.

[33] A.E. Gripp, R.G. Gordon, Current plate velocities relative to the hotspots incorporating the NUVEL-1 global plate motion model, Geophys. Res. Lett. 17 (1990) 1109 1112.

[34] R.D. Mueller, W.R. Roest, J.-Y. Royer, L.M. Gahagan, J.G. Sclater, A Digital Age Map of the Ocean Floor, Reference Series 93-30, Scripps Instit. Ocean., 1993.

[35] R.M. Russo, C.J. Wolfe, E.A. Okal, P.G. Silver, S.C. Solomon, Shear-wave splitting beneath the Hawaiian Islands, Trans. Am. Geophys. Union 79 (1998) S208.

[36] M. Becker, R. Brousse, G. Guille, H. Bellon, Phases d'erosion-comblement de la vallee de la Papenoo et volcanisme sub-recent a Tahiti, en relation avec l'evolution des Iles de la Societe, Mar. Geol. 16 (1974) M71-M77.

[37] R.D. Jarrard, D.A. Clague, Implications of Pacific Island and seamount ages for the origin of volcanic chains, Rev. Geophys. Space Phys. 15 (1977) 57-76.

[38] V. Babuska, J. Plomerova, J. Sileny, Models of seismic anisotropy in the deep continental lithosphere, Phys. Earth. Planet. Int. 78 (1993) 167-191.

[39] D. Alsina, R. Snieder, Small-scale sublithospheric continental mantle deformation: constraints from SKS splitting observations, Geophys. J. Int. 123 (1995) 431-448.

[40] J. Talandier, E.A. Okal, Crustal structure in the Society and Tuamotu islands, French Polynesia, Geophys. J. R. Astron. Soc. 88 (1987) 499-528.

[41] A.M. Dziewonski, D.L. Anderson, Preliminary reference Earth model, Phys. Earth Planet. Int. 25 (1981) 297-356.

[42] C. Nishimura, D. Forsyth, The anisotropic structure of the upper mantle in the Pacific, Geophys. J. Int. 96 (1989) 203-226.

[43] J.-P. Montagner, T. Tanimoto, Global upper mantle tomography of seismic velocities and anisotropies, J. Geophys. Res. 96 (1991) 20337-20351.

[44] D.W. Peate, The Paraná-Etendeka Province, in: J.J. Mahoney, M.F. Coffin (Eds.), Large Igneous Provinces: Continental, Oceanic and Planetary Flood Volcanism, AGU Geophysical Monograph 100, Am. Geophys. Union, Washington, DC, 1997, pp. 335-355.

[45] J.J. Mahoney, Deccan traps, in: J.D. Macdougal (Ed.), Continental Flood Basalts, Kluwer Academic Publishers, Dordrecht, 1988, pp. 151-194.

[46] M.T. Woods, E.A. Okal, Rayleigh-wave dispersion along the Hawaiian Swell; a test of lithospheric thinning by thermal rejuvenation at a hotspot, Geophys. J. Int. 125 (1996) 325-339.

[47] B.M. Gomer, E.A. Okal, Multiple ScS probing of the Ontong-Java Plateau, Phys. Earth. Planet. Inter. (2001), submitted for publication.

[48] K.D. Collerson, S. Hapugoda, B.S. Kamber, Q. Williams, Rocks from the mantle transition zone; majorite-bearing xenoliths from Malaita, Southwest Pacific, Science 288 (2000) 1215-1223.

[49] T.H. Jordan, The continental tectosphere, Rev. Geophys. Space Phys. 13 (1975) 1-12.

[50] W.H.F. Smith, D.T. Sandwell, Global sea floor topography from satellite altimetry and ship depth soundings, Science 277 (1997) 1956-1962. 